Article

\title{
Salts and Co-Crystalline Assemblies of Tetra(4-Pyridyl)Ethylene with Di-Carboxylic Acids
}

\author{
Moustafa T. Gabr and F. Christopher Pigge * \\ Department of Chemistry, University of Iowa, Iowa City, IA 52242, USA; \\ moustafatarekahmedibrahim-gabr@uiowa.edu \\ * Correspondence: chris-pigge@uiowa.edu; Tel.: +1-319-335-3805
}

Received: 22 December 2017; Accepted: 15 January 2018; Published: 17 January 2018

\begin{abstract}
Tetraarylethylene derivatives are emerging as an increasingly important family of supramolecular building blocks in both solution phase and the solid state. The utility of tetraarylethylenes stems from appealing structural features (rigidity and symmetry) and their propensity to exhibit aggregation induced emission (AIE). In an effort to investigate the luminescent sensing ability of heteroaromatic tetraarylethylenes, we previously prepared tetra(4-pyridyl)ethylene and characterized its solution phase AIE properties. We here report the successful incorporation of tetra(4-pyridyl)ethylene into three distinct salts and co-crystalline assemblies with three organic di-carboxylic acids (oxalic acid, malonic acid, and fumaric acid). Interactions between the tetra(pyridyl)ethylene and di-acid components were found to vary from conventional to charge-assisted hydrogen bonding according to the extent of proton transfer between the acid and pyridine groups. Notably, the formation of pyridinium-carboxylate adducts in the salts does not appear to be strongly correlated with acid pKa. Three distinct network topologies were observed, and all featured the bridging of two or three tetra(pyridyl)ethylene groups through di-acid linkers. Crystalline assemblies also retained the AIE activity of tetra(pyridyl)ethylene and were luminescent under UV light. As tetra(4-pyridyl)ethylene features four Lewis basic and potentially metal ligating pyridine rings in a relatively well-defined geometry, this compound represents an attractive building block for the design of additional crystalline organic and metal-organic functional materials.
\end{abstract}

Keywords: supramolecular chemistry; crystal engineering; co-crystals; hydrogen bonded organic frameworks; aggregation induced emission

\section{Introduction}

The design of functional crystalline materials has emerged as a principal objective of contemporary solid state supramolecular chemistry. It is envisioned that crystalline assemblies prepared from appropriate combinations of organic and/or metal-organic building blocks will afford functional materials that exhibit targeted bulk properties. Desirable bulk properties include inter alia porosity, catalysis, magnetism, conductivity, luminescence, and non-linear optical activity [1-12]. Of these targeted functions, the construction of porous crystalline materials has garnered considerable attention, in large part spurred by the desire to identify energy-related materials that can be potentially used for reversible gas storage [13-15].

A common strategy implemented in many crystal engineering approaches to functional materials aims to exploit well-defined elements of molecular recognition or metal ligating ability that are arranged in pre-defined patterns about rigid or semi-rigid organic building blocks to mediate supramolecular assembly. For example, aromatic polycarboxylic acids, such as terephthalic acid (1,4-benzene dicarboxylic acid), isophthalic acid (1,3-benzene dicarboxylic acid), and trimesic acid (1,3,5-benzene tricarboxylic acid), have provided a wealth of robust crystalline assemblies (both purely 
organic as well as metal-organic) with diverse properties [5,6,10]. Similarly, N-functionalized Lewis basic building blocks (such as bipyridine and related polypyridines) have proven to be valuable crystal engineering tools [16]. Benzene polycarboxylic acids, polypyridine derivatives, and related congeners offer predictable and geometrically defined supramolecular or metal ligating interactions. Consonant with this strategy, new rigid or semi-rigid organic architectures that can be decorated with hydrogen bonding and/or metal ligating moieties offer opportunities to expand the crystal engineering toolbox and further facilitate construction of additional functional materials.

In this context, tetraarylethylenes represent an attractive platform for the construction of novel crystalline assemblies. The parent hydrocarbon tetraphenylethylene (1, Figure 1 ) and numerous substituted derivatives are known to exhibit the phenomenon of aggregation-induced emission (AIE) in which enhanced luminescence is observed upon the restriction of intramolecular bond rotations due to aggregation of tetraarylethylene molecules in solution (e.g., in the presence of poor solvents) or in the solid state $[17,18]$. This general property of tetraarylethylenes coupled with a geometrically appealing molecular structure has resulted in studies examining the utility of tetraarylethylene derivatives in solution phase and solid state supramolecular assembly processes, often with the aim of capitalizing on enhanced luminescence to deliver new optical or sensing materials $[19,20]$. Indeed, several crystalline luminescent metal organic frameworks (MOFs) have been prepared using the symmetrical tetraphenylethylene carboxylic acid (2) as well as the extended biphenylethylene analogue (3) as rigid metal ligating components [21-35]. Additionally, we have investigated the electrooptical properties of crystalline organic assemblies constructed from phenoxyacetic acid (4) and bis(pyridine) derivatives [36]. We have also characterized halogen bond-mediated self-assembly and luminescence in crystals of tetraphenylethylene halophenyl esters (5) [37]. The tetrapyridine derivative (6), featuring four pyridine units grafted onto the periphery of tetraphenylethylene [38], has also been utilized as a metal ligating component in several MOFs, as well as a ligand in dynamic solution phase metal-organic assemblies [39-50]. The solid state halogen bond accepting ability of 6 in combination with diiodoarene halogen bond donors has also been examined [51].<smiles>c1ccc(C(=C(c2ccccc2)c2ccccc2)c2ccccc2)cc1</smiles>
(tetraphenylethylene)<smiles>[R]c1ccc(C(=C(c2ccc([R])cc2)c2ccc([R])cc2)c2ccc([R])cc2)cc1</smiles>

$2 \mathrm{R}=\mathrm{CO}_{2} \mathrm{H}$

$3 \mathrm{R}=4-\mathrm{C}_{6} \mathrm{H}_{4} \mathrm{CO}_{2} \mathrm{H}$

$4 \mathrm{R}=\mathrm{OCH}_{2} \mathrm{CO}_{2} \mathrm{H}$

$5 \mathrm{R}=\mathrm{O}_{2} \mathrm{CC}_{6} \mathrm{H}_{4} \mathrm{X}(\mathrm{X}=\mathrm{Br}, \mathrm{I})$<smiles>c1cc(-c2ccc(C(=C(c3ccc(-c4ccncc4)cc3)c3ccc(-c4ccncc4)cc3)c3ccc(-c4ccncc4)cc3)cc2)ccn1</smiles><smiles>c1cc(C(=C(c2ccncc2)c2ccncc2)c2ccncc2)ccn1</smiles><smiles>O=C(O)C(=O)O</smiles><smiles>O=C(O)CC(=O)O</smiles>

malonic acid<smiles>O=C(O)/C=C/C(=O)O</smiles>

Figure 1. Tetraphenylethylene (1) and tetraarylethylene derivatives (2-6) with proven utility as crystal engineering building blocks. Described below are the structures of three salts and co-crystals assembled from 7 and oxalic acid, malonic acid, and fumaric acid. 
Recently, we have initiated research aimed at developing small-molecule sensors for select analytes based on the metal chelating ability of poly(pyridyl) tetraarylethylenes in which two or more phenyl rings in tetraphenylethylene have been replaced with pyridine groups [52-54]. During the course of these studies, we also prepared tetra(4-pyridyl)ethylene (7) and characterized its solution phase AIE luminescent properties [54]. This tetra(pyridine) derivative resembles its larger analogue 6 in that the four pyridine rings are oriented in more or less fixed positions about the central alkene linkage to provide geometrically well-defined Lewis basic sites that are available for intermolecular interactions. We envision that synthetic accessibility and desirable molecular features will render 7 a useful building block in a range of crystal engineering applications. In preliminary efforts to explore the solid state supramolecular chemistry of 7 , we report here the structures of three crystalline networks between 7 and oxalic, malonic, and fumaric acids.

\section{Materials and Methods}

Tetra(pyridyl)ethylene (7) was synthesized as reported previously [54]. Co-crystals of 7 and the three dicarboxylic acids were obtained under similar conditions. A capped sample vial containing tetra(pyridine) $7(33.6 \mathrm{mg}, 0.1 \mathrm{mmol})$ and $0.2 \mathrm{mmol}$ of the dicarboxylic acid in $6 \mathrm{~mL}$ of a 2:1 $\mathrm{MeOH} /$ acetone solution was heated in a $60^{\circ} \mathrm{C}$ water bath for $1 \mathrm{~h}$ to obtain a homogeneous solution. The vial was then allowed to cool to room temperature. Slow evaporation of solvent under ambient conditions deposited X-ray quality single crystals. Diffraction data were collected on a Nonius Kappa CCD diffractometer (Bruker-Nonius, Delft, The Netherlands) equipped with Mo K $\alpha$ radiation with $\lambda=0.71073 \AA$. Crystallographic data is shown in Table S1. Structures were solved by direct methods, and data were refined by full matrix least squares refinement of $\mathrm{F}^{2}$ against all reflections. Supplementary crystallographic data for this paper can be found in CCDC 1590576-1590578. This data can be obtained free of charge from the Cambridge Crystallographic Data Centre via www.ccdc.cam.ac.uk/structures.

\section{Results and Discussion}

Tetra(pyridyl)ethylene (7) was prepared via double Suzuki coupling between 1,1-dibromo-2,2bis(4-pyridyl)ethylene and 4-pyridyl boronic acid as described previously [54]. Initial attempts to prepare co-crystals involved mixing 7 with terephthalic or isophthalic acid in different solvents followed by slow evaporation, but crystalline materials were not deposited under these conditions. We speculate that the combined rigidity of $\mathbf{7}$ and the benzene dicarboxylic acids may not be compatible with efficient crystal nucleation and growth. Consequently, we selected linear acyclic dicarboxylic acids as crystallization partners with the expectation that the smaller size and greater flexibility of these acids may be conducive to co-crystallization with 7 . Gratifyingly, slow evaporation of methanol/acetone solutions containing 2:1 ratios of di-acid/7 yielded crystalline salts or co-crystalline assemblies. Of the simple di-acids screened in this study, $\mathrm{X}$-ray quality single crystals were obtained from 7 and oxalic, malonic, and fumaric acids, while microcrystalline powders unsuitable for X-ray analysis were obtained from succinic, glutaric, and adipic acids.

Crystals of 7 (oxalic acid) 2 were formed with a 2:1 ratio of oxalic acid / 7 along with seven $\mathrm{H}_{2} \mathrm{O}$ molecules of hydration. Crystallographic data is provided in Table S1. The asymmetric unit is comprised of one molecule of oxalic acid, 0.5 molecules of 7 , and $3.5 \mathrm{H}_{2} \mathrm{O}$ molecules. The $\mathrm{C}-\mathrm{O}$ bond lengths in the oxalic acid component are all comparable and range from 1.288 to $1.219 \AA$, indicative of doubly deprotonated oxalate(2-) anions. Each pyridine group has been converted to a protonated pyridinium cation as evidenced by intra-annular N-C-N angles of $\sim 121^{\circ}$. These angles are significantly larger than comparable bond angles found in neutral pyridines (typically $\sim 116^{\circ}$ ) [55]. Oxalate and pyridinium groups are connected through a network of charge-assisted hydrogen bonds as shown in Figure 2. One pyridinium group engages oxalate in a bifurcated $\mathrm{H}$-bonding interaction, but the $\mathrm{H} 4-\mathrm{O} 2$ distance is much shorter than the H4-O1 distance (1.806 $\AA$ and $2.319 \AA$, respectively). The O1 oxygen of oxalate is also involved in a second strong $\mathrm{H}$-bonding interaction with $\mathrm{H} 10$ of a neighboring molecule 
of 7 that serves to bridge two tetraarylethylenes (H10-O1 $d=1.474 \AA$ ). Individual molecules of 7 adopt a propeller-like conformation typical of tetraarylethylenes [17]. The oxalate ions are further linked through an extensive network of $\mathrm{H}$-bonds emanating from discrete $\mathrm{T} 4(1)$ water tetramers (Figure 3A) [56]. Hydrogen bond distances from $\mathrm{H}_{2} \mathrm{O}$ to oxalate and among $\mathrm{H}_{2} \mathrm{O}$ molecules range from 1.833 to $2.080 \AA$ A. Two views of the extended packing are illustrated in Figure 3B,C. Figure 3B shows the view down $c$ in which offset stacked columns of alternating bridged tetra(pyridinium)ethylenes are separated by oxalate-water clusters, while Figure $3 C$ depicts the packing down $b$.

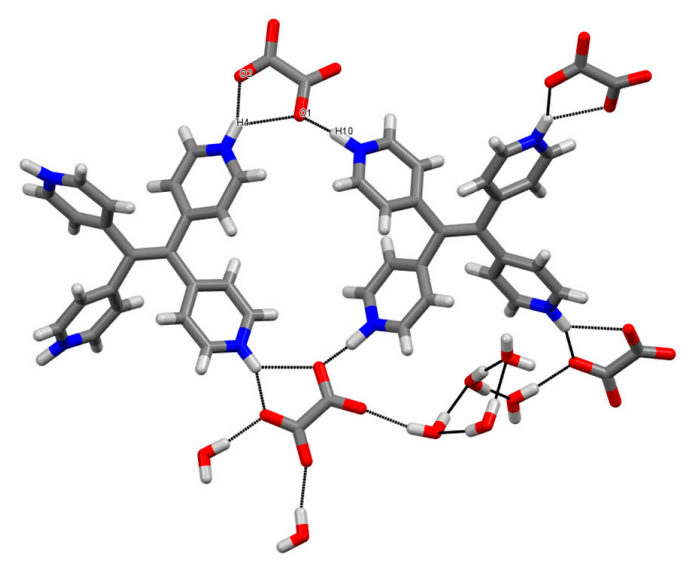

Figure 2. Charge-assisted H-bonding interactions in oxalate-bridged tetra(pyridinium)ethylene co-crystals.

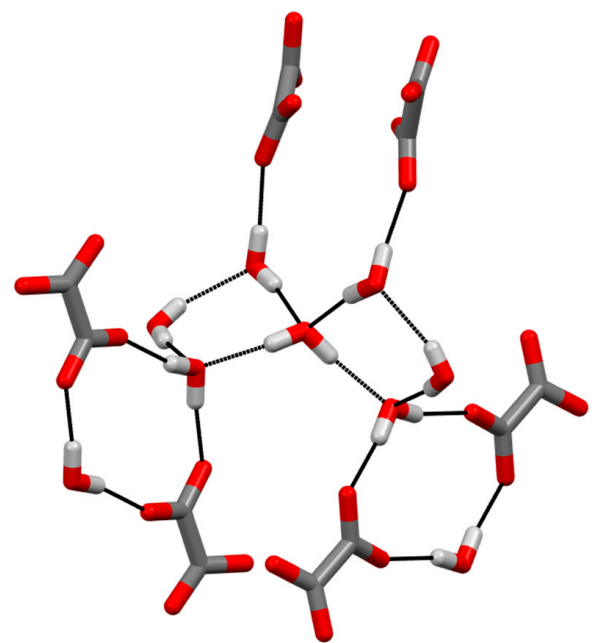

(A)

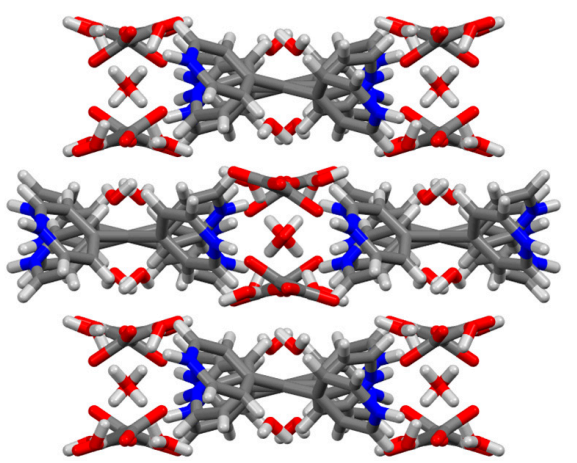

(B)

Figure 3. Cont. 


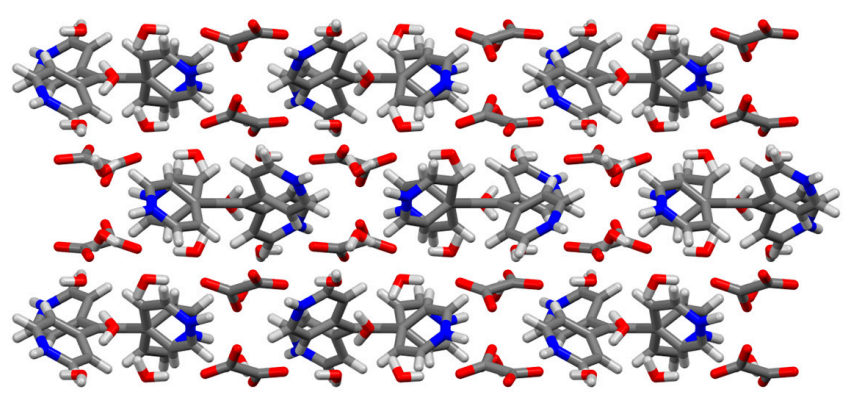

(C)

Figure 3. (A) Tetrameric water clusters linking oxalate ions in 7 (oxalic acid) $27 \mathrm{H}_{2} \mathrm{O} ;(\mathbf{B}, \mathbf{C})$ Two views of the extended packing in 7 (oxalic acid) ${ }_{2} 7 \mathrm{H}_{2} \mathrm{O}$ : (B) down $c$; (C) down $b$.

The structure of $\mathbf{7}$ (malonic acid) $)_{1.5}$ exhibits significantly different features compared to the oxalic acid salt described above. First, solvate-free close-packed crystals were obtained in stoichiometry consisting of one molecule of $\mathbf{7}$ and 1.5 molecules of malonic acid (crystallographic data is provided in Table S1). The malonic acid groups are present as neutral carboxylic acids (rather than carboxylate anions as observed for oxalic acid). This is clearly evident by differences in the two $\mathrm{C}-\mathrm{O}$ bond lengths in each carboxylic acid unit $(1.202+1.309 \AA ; 1.203+1.314 \AA ; 1.202+1.306 \AA)$. Each unique carboxylic acid residue engages a pyridine ring of 7 in a conventional (neutral) hydrogen bonding interaction (Figure 4, H-N distances range from 1.685 to $1.847 \AA$, O-N distances 2.655-2.680 ̊). The fourth pyridine ring of 7 , however, does not participate in any H-bonding interactions. Evidence that the pyridines are acting as $\mathrm{H}$-bond acceptors (and not as pyridinium $\mathrm{H}$-bond donors) is further provided by the intra-annular $\mathrm{C}-\mathrm{N}-\mathrm{C}$ angles (which range from 116.91 to $117.69^{\circ}$ ) [55]. These angles are similar to the angle found in the remaining non-H-bonded pyridine $\left(115.93^{\circ}\right)$ and are significantly smaller than the analogous angles found in tetra(pyridinium)ethylene described above.

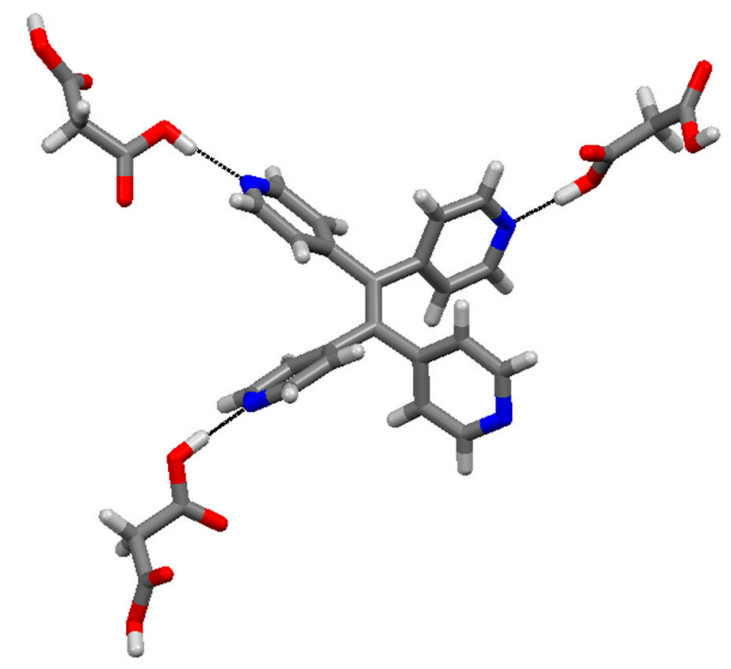

Figure 4. Hydrogen bonding interactions in 7 (malonic acid) 1.5 co-crystals.

The structural topology observed in co-crystals of 7 (malonic acid) 1.5 can be described as a $(6,3)$ net [57]. Each molecule of $\mathbf{7}$ functions as a three-connected node bridged by malonic acid linkers. Six malonic acid molecules and six molecules of $\mathbf{7}$ comprise a cyclic motif that share common edges with adjacent cyclic assemblies, affording two-dimensional layers shown in Figure 5. The large cavities evident in Figure 5 (cross-sectional dimensions of $\sim 24 \times 34 \AA$ ) are filled with two additional intertwined $(6,3)$ nets as shown in Figure 6. Offset stacking of 2D layers then completes the structure. 


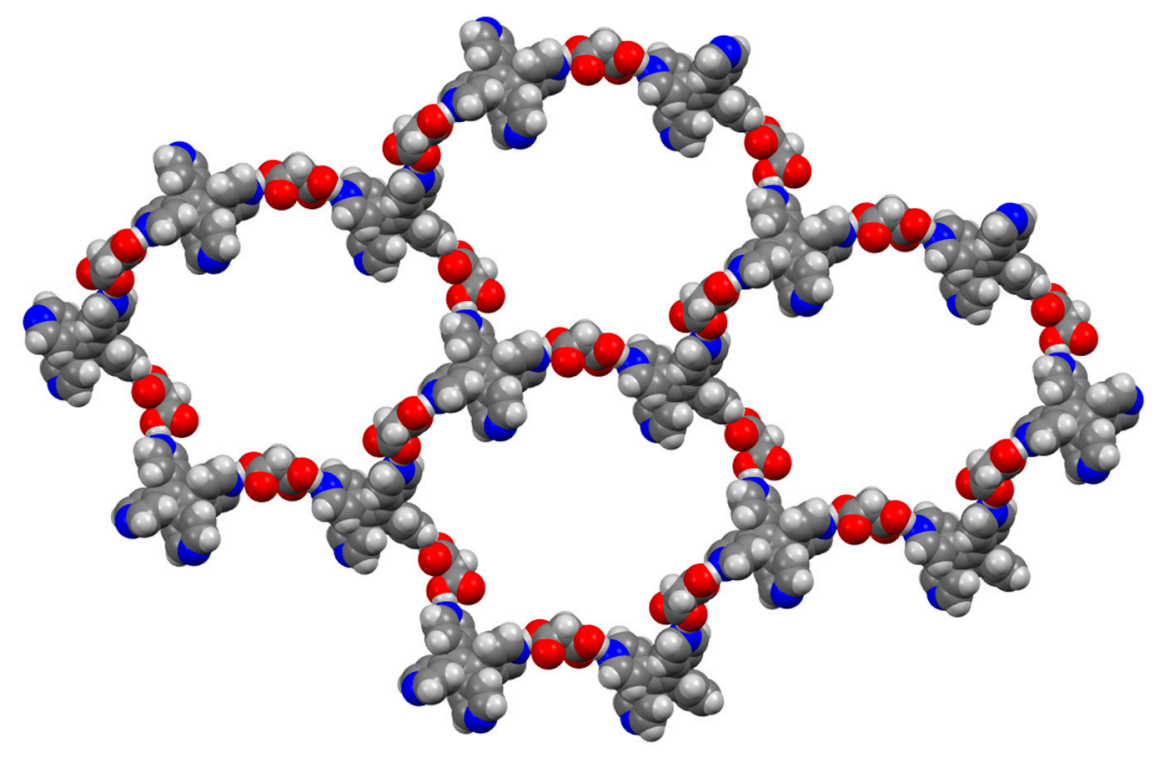

Figure 5. Spacefilling representation of a $2 \mathrm{D}(6,3)$ net formed from 3-connected tetra(pyridyl)ethylene nodes and malonic acid linkers.

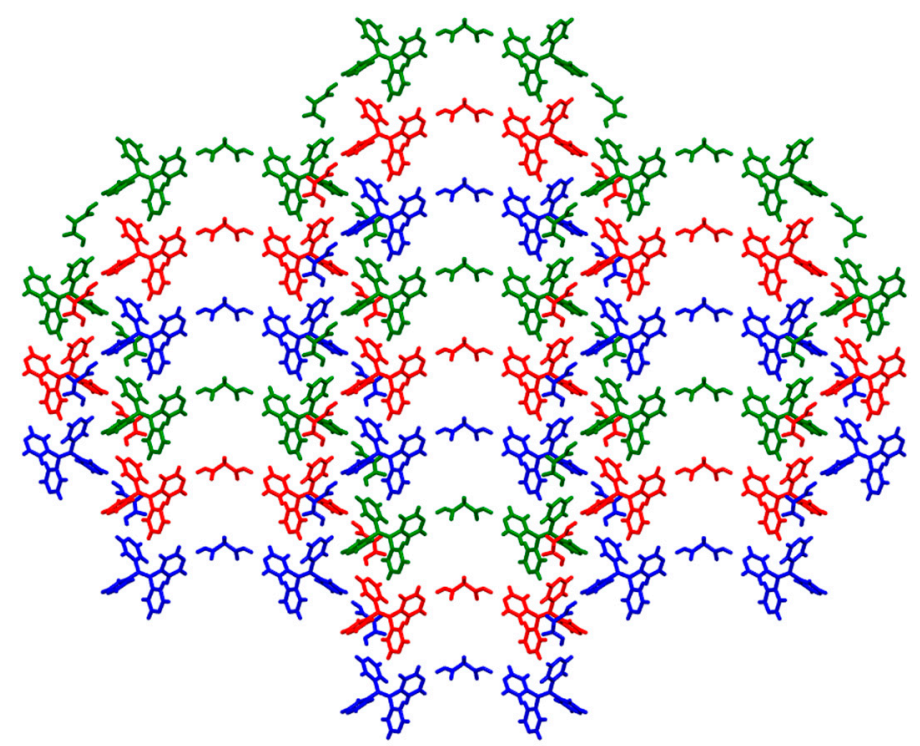

Figure 6. Interdigitation of three $(6,3)$ nets in 7 (malonic acid) $)_{1.5}$. Three identical independent $(6,3)$ networks are color coded red, green, and blue.

Crystals of $\mathbf{7}$ and fumaric acid were also successfully grown. X-ray diffractometry revealed a close-packed structure of stoichiometry 7 (fumaric acid) ${ }_{4}$ (crystallographic data is shown in Table S1). The asymmetric unit consists of a 0.5 tetra(pyridyl)ethylene molecule that features one neutral pyridine $\left(\mathrm{N}-\mathrm{C}-\mathrm{N}\right.$ angle $\left.117.93^{\circ}\right)$ and one protonated pyridinium cation (N-C-N angle $\left.122.54^{\circ}\right)$. Additionally, two molecules of fumaric acid are present, one of which exists as a mono-anion as evidenced by similar $\mathrm{C}-\mathrm{O}$ bond lengths at the anionic carboxylate terminus (1.240 and 1.262 $\mathrm{A}$ ) compared to distinctly shorter and longer $\mathrm{C}-\mathrm{O}$ bond lengths at the carboxylic acid terminus (1.212 and $1.316 \AA$ ). The second fumaric acid molecule is present as a neutral dicarboxylic acid with $\mathrm{C}=\mathrm{O}$ bond lengths of 1.202 and $1.211 \AA$ and $\mathrm{C}-\mathrm{OH}$ bond lengths of 1.322 and $1.312 \AA$. The protonated pyridinium cations in each full molecule of 7 are in a trans-1,2-orientation about the central ethylene bond. Each pyridinum moiety is engaged with the carboxylate terminus of a fumarate mono-anion to form a cyclic hydrogen bonded 
motif featuring a pyridinium-carboxylate charge-assisted hydrogen bond $\left(\mathrm{NH}^{+}-\mathrm{O}^{-}\right.$distance $2.008 \AA$, $\mathrm{N}-\mathrm{H}-\mathrm{O}$ angle $147.05^{\circ}, \mathrm{C}-\mathrm{O}-\mathrm{H}$ angle $126.54^{\circ}$ ) and a $\mathrm{C}-\mathrm{H} \cdots \mathrm{O}$ hydrogen bond (pyCH-O distance $2.400 \AA$ ) [58]. In complementary fashion, the neutral pyridine rings in 7 each engage the neutral carboxylic acid terminus of fumarate mono-anion in a conventional hydrogen bonding interaction (OH-N distance $1.826 \AA, \mathrm{O}-\mathrm{H}-\mathrm{N}$ angle $169.26^{\circ}$ ). Thus, two fumarate mono-anions serve to bridge two bis(pyridyl)-bis(pyridinium) ethylenes, ultimately giving rise to two-dimensional hydrogen bonded chains, as shown in Figure 7.

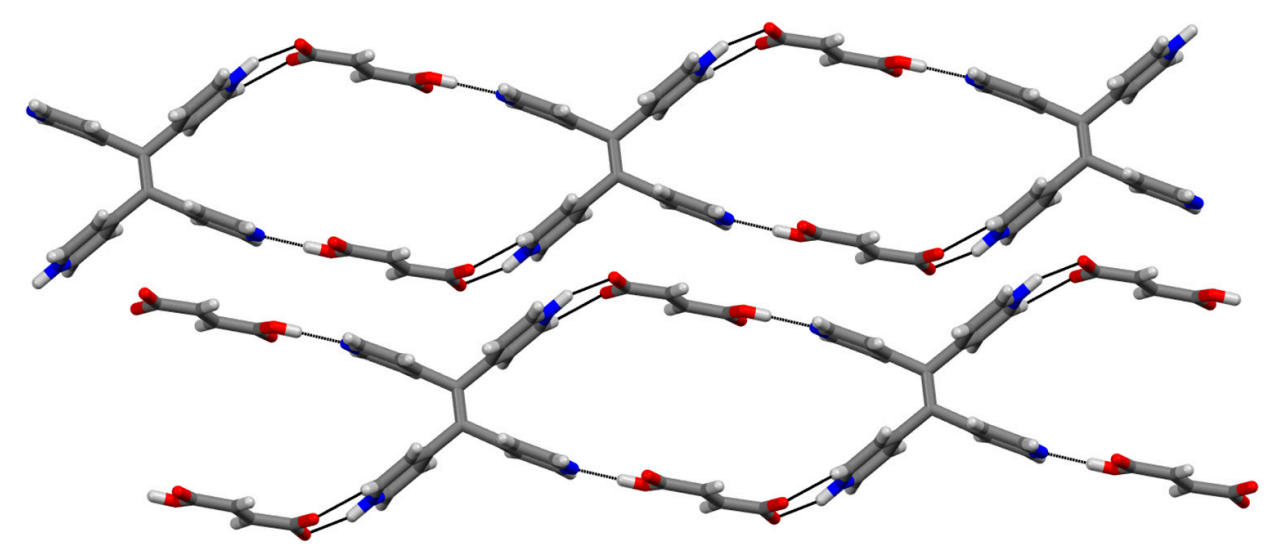

Figure 7. Charge-assisted parallel H-bonded chains of fumarate mono-anion and bis(pyridyl)-bis (pyridinium)ethylene.

The neutral fumaric acid molecules are observed to support the charge-assisted carboxylate-pyridinium hydrogen bonding interactions as shown in Figure 8. A distorted hydrogen bonded trimer involving the carboxylate terminus of fumarate mono-anion, a carboxylic acid group of neutral fumaric acid, and a pyridinium residue orients fumaric acid groups perpendicular to the $2 \mathrm{D}$ hydrogen bonded chains described above. The remaining carboxylic acids of neutral fumaric acid groups are hydrogen bonded to carboxylate oxygen atoms of fumarate mono-anions found in adjacent $\mathrm{H}$-bonded chains. Thus, the fumaric acid components serve to connect parallel chains of $\mathbf{7}$ fumarate hydrogen bonded polymers to form cross-linked sheets.
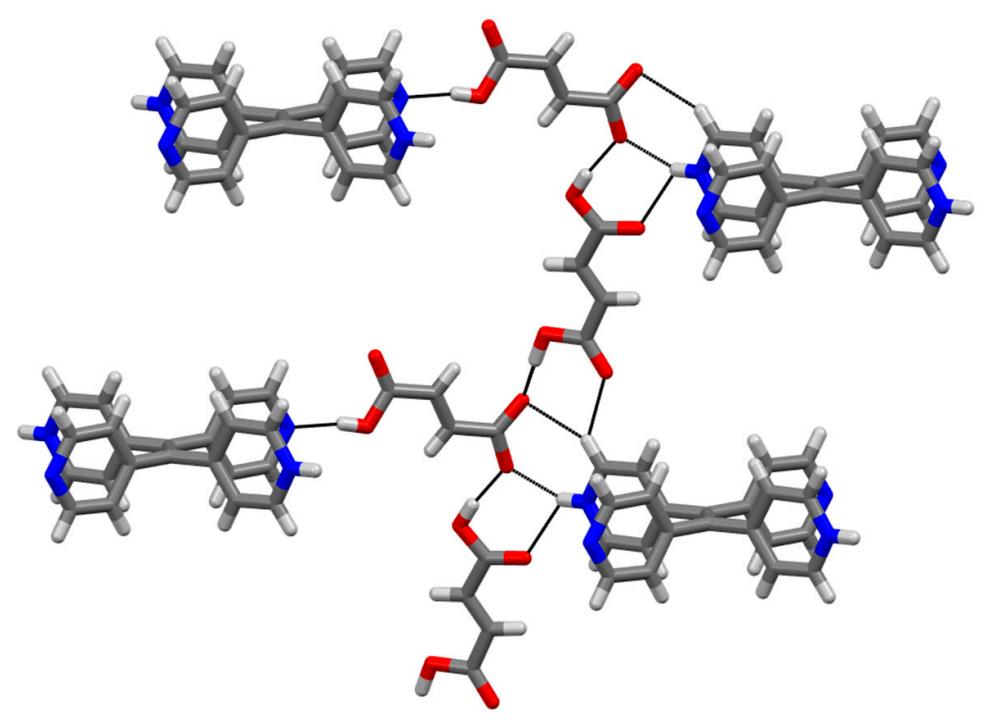

Figure 8. 2D chains of $\mathbf{7}$ fumarate assemblies are connected in the third dimension by hydrogen bonding to neutral fumaric acid components. 
Interdigitation of a second network of fumaric acid-linked 7 fumarate chains gives rise to an alternating sheet-like structure with an $A B A B$ stacking motif. The elliptical openings in the supramolecular macrocycles formed through fumarate-pyridine/pyridinium H-bonding in one sheet (see Figure 7) possess diagonal 2D cross-sections of $\sim 1 \mathrm{~nm}$ (i.e., distance from pyridine to pyridine $\mathrm{N}$ atoms and pyridinium to pyridinium $\mathrm{N}$ atoms). These openings are occupied by two neutral fumaric acid molecules that support the charge-assisted carboxylate-pyridinium hydrogen bonding interactions connecting two adjacent offset parallel sheets. Two views of this packing arrangement are shown in Figure 9 with identical independent networks color coded green and red.

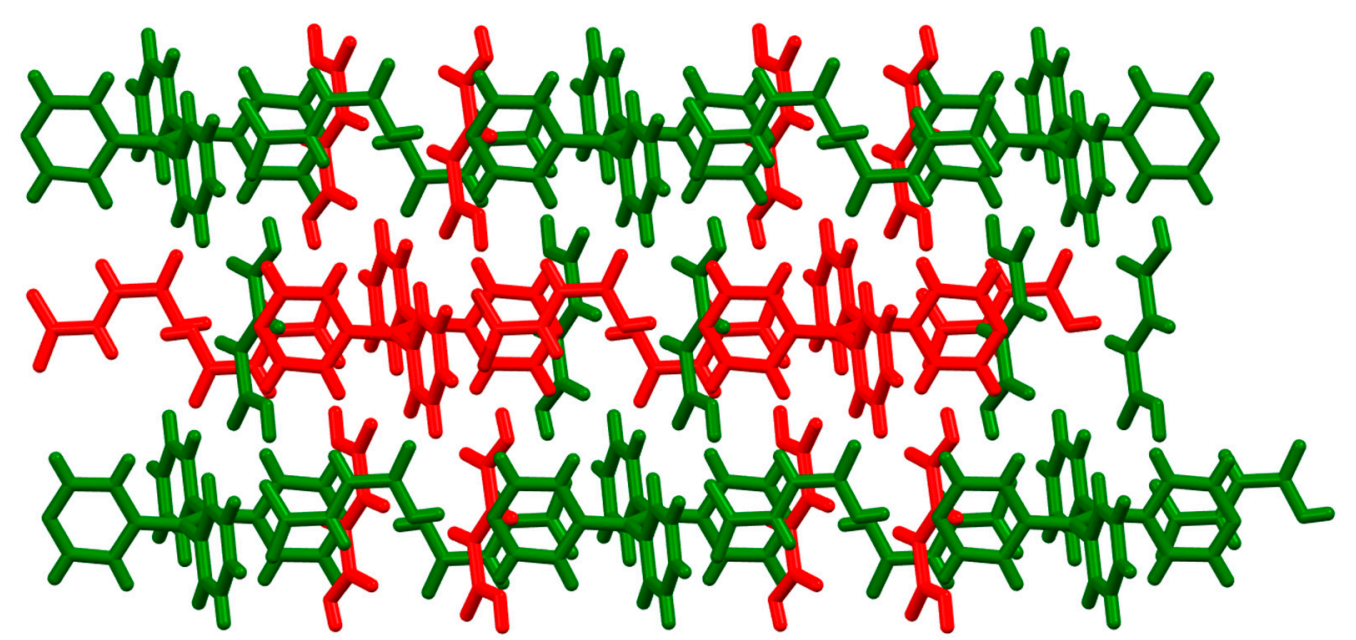

(A)

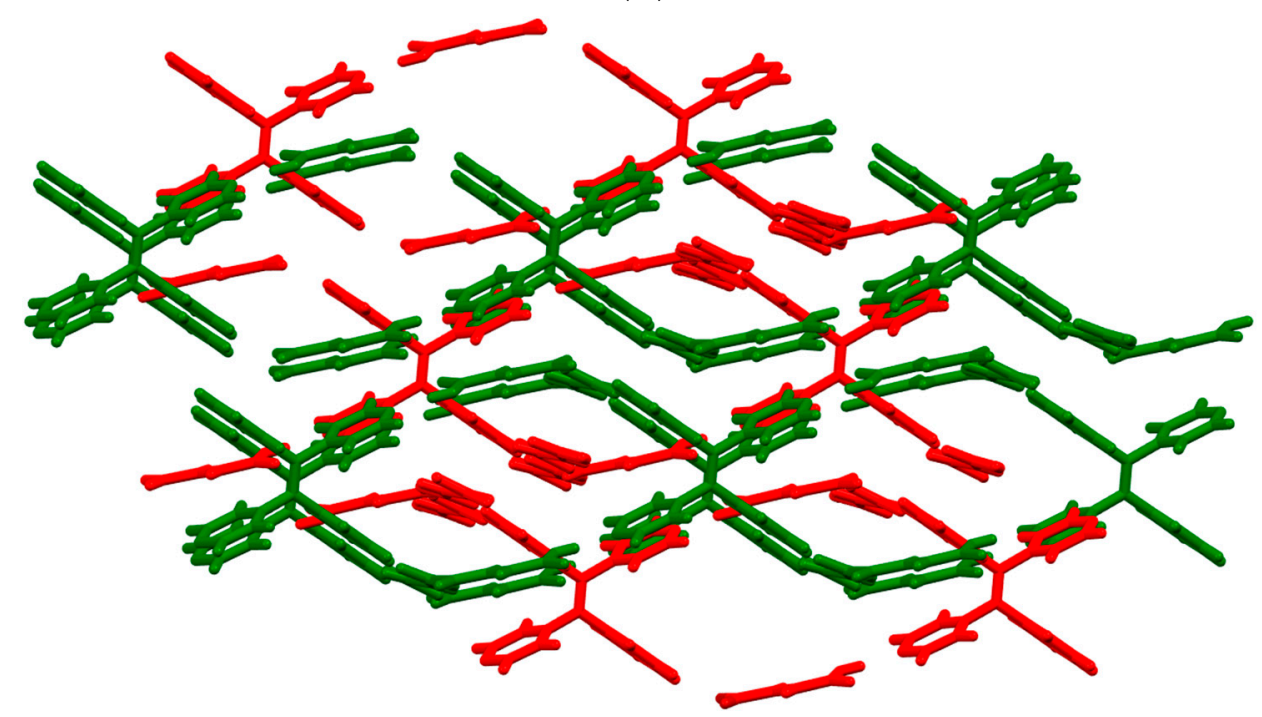

(B)

Figure 9. Interpenetration of fumaric acid cross-linked 7 fumarate sheets. Identical independent networks are color coded green and red. (A) shows the view down the $c$ axis (parallel to sheet axes); (B) shows the view roughly perpendicular to the sheet axes with the ABA stacking motif represented by green-red-green networks.

Three distinct crystalline organic composites have been obtained from tetra(4-pyridyl)ethylene 7 and three different linear dicarboxylic acids. Interestingly, the assemblies characterized in this study feature $\mathbf{7}$ in three different formal protonation states: a tetra-protonated tetracation in combination with oxalic acid, a di-protonated dication in the presence of fumaric acid, and a neutral tetra(pyridine) in the presence of malonic acid. Thus, it appears that the solid state basicity of $\mathbf{7}$ can respond to an 
acidic environment in a manner that facilitates the formation of stable crystalline networks. Although oxalic acid is the strongest dicarboxylic acid among the three utilized in this study (pKa values of 1.27 and 4.28$)$, both malonic and fumaric acid possess comparable $\mathrm{pKa}_{1}$ ( 2.85 and 3.02, respectively), and oxalic and fumaric acid possess comparable $\mathrm{pKa}_{2}$ (4.28 and 4.39, respectively). It appears, then, that consideration of $\mathrm{pKa}$ alone is insufficient to explain the conversion of $\mathbf{7}$ to poly(pyridindium) cations, and the tendency of $\mathbf{7}$ to experience protonation in the solid state may be strongly influenced by self-assembly dynamics along with the size and shape of acidic additives.

\section{Conclusions}

The results of this study demonstrate the capability of Lewis basic tetra(pyridyl)ethylene (7) to participate in co-crystal and salt formation with organic acids. The distinct topologies of the crystalline assemblies characterized in this work provide a glimpse of the varied architectures potentially accessible from small-molecule building blocks such as 7 and structurally related analogues. Additionally, insertion of metal ions into poly(pyridyl)ethylene-poly(acid) networks offer opportunities for construction of novel metal-organic frameworks that may exhibit topologies and properties distinct from those obtained using significantly larger tetraarylethylene components such as 6 (see Figure 1). Research along these lines is currently underway. Finally, a defining feature of tetraarylethylene assemblies is the luminescent properties that often emerge upon restriction of intramolecular bond rotation (i.e., AIE effects). The AIE activity of tetra(pyridyl)ethylene $\mathbf{7}$ previously established in solution phase studies is retained in the solid state assemblies prepared in this work. For example, the luminescence of $\mathbf{7}$ (fumaric acid) ${ }_{4}$ is visible to the naked eye as shown in Figure 10. The other two crystalline assemblies displayed similar luminescence, as shown in Figures S1 and S2 (see Supplementary Materials).

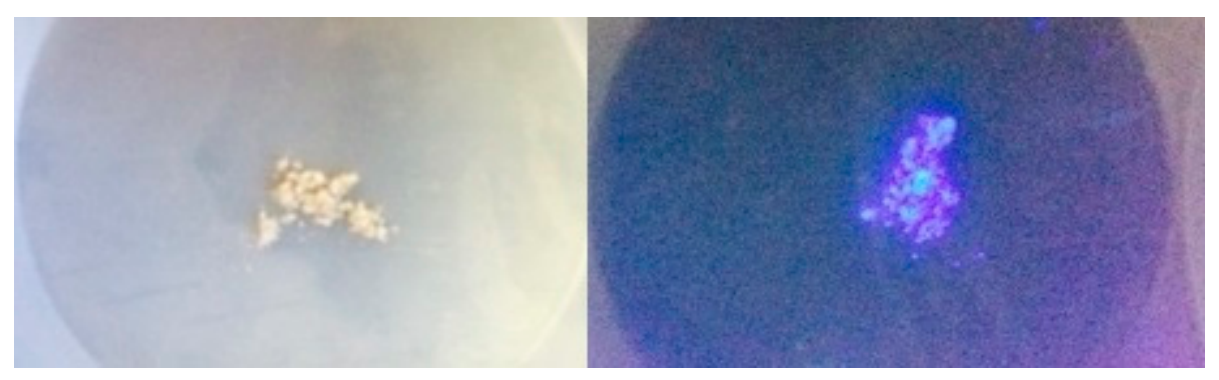

Figure 10. Luminescence of 7 (fumaric acid) ${ }_{4}$ as revealed in photographs of microcrystalline samples taken under ambient light (left) and UV light (365 nm) (right).

Tetra(pyridyl)ethylene (7) is a promising supramolecular building block with appealing molecular and structural features. Moreover, 7 itself is easily prepared in good overall yield, and numerous additional structural analogues should become available via similar synthetic sequences. Additional applications of heteroarylethylenes in both organic and metal-organic crystal engineering are under investigation, and it is envisioned that these efforts will offer new approaches to a variety of functional crystalline materials.

Supplementary Materials: The following are available online at www.mdpi.com/2073-4352/8/1/41/s1. Table S1: crystallographic data. Figure S1: photograph illustrating luminescent properties of 7 (oxalic acid). Figure S2: photograph illustrating luminescent properties of 7 (malonic acid).

Acknowledgments: We thank the Department of Chemistry, University of Iowa, for partial support of this work. We thank Dale C. Swenson (University of Iowa) for assistance with X-ray crystallography.

Author Contributions: F. Christopher Pigge conceived the work; F. Christopher Pigge and Moustafa T. Gabr designed the experiments and analyzed the data; Moustafa T. Gabr performed the experiments; F. Christopher Pigge wrote the paper.

Conflicts of Interest: The authors declare no conflict of interest. 


\section{References}

1. Mahmudov, K.T.; Kopylovich, M.N.; Guedes da Silva, M.F.C.; Pombeiro, A.J.L. Non-covalent interactions in the synthesis of coordination compounds: Recent advances. Coord. Chem. Rev. 2017, 345, 54-72. [CrossRef]

2. Seoane, B.; Castellanos, S.; Dikhtiarenko, A.; Kapteijn, F.; Gascon, J. Multi-scale crystal engineering of metal organic frameworks. Coord. Chem. Rev. 2016, 307, 147-187. [CrossRef]

3. Ok, K.M. Toward the rational design of novel noncentrosymmetric materials: Factors influencing the framework structures. Acc. Chem. Res. 2016, 49, 2774-2785. [CrossRef] [PubMed]

4. Yassar, A. Recent trends in crystal engineering of high-mobility materials for organic electronics. Polym. Sci. Ser. C 2014, 56, 4-19. [CrossRef]

5. Liu, J.; Chen, L.; Cui, H.; Zhang, J.; Zhang, L.; Su, C.-Y. Applications of metal-organic frameworks in heterogeneous supramolecular catalysis. Chem. Soc. Rev. 2014, 43, 6011-6061. [CrossRef] [PubMed]

6. Desiraju, G.R. Crystal engineering: From molecule to crystal. J. Am. Chem. Soc. 2013, 135, $9952-9967$. [CrossRef] [PubMed]

7. Biradha, K.; Santra, R. Crystal engineering of topochemical solid state reactions. Chem. Soc. Rev. 2013, 42, 950-967. [CrossRef] [PubMed]

8. Zou, C.; Wu, C.-D. Functional porphyrinic metal-organic frameworks: Crystal engineering and applications. Dalton Trans. 2012, 41, 3879-3888. [CrossRef] [PubMed]

9. Mastalerz, M. Rational design of multifunctional nanopores by mixing matching molecules. Angew. Chem. Int. Ed. 2012, 51, 584-586. [CrossRef] [PubMed]

10. Li, J.-R.; Sculley, J.; Zhou, H.-C. Metal-Organic frameworks for separations. Chem. Rev. 2012, 112, 869-932. [CrossRef] [PubMed]

11. Kurmoo, M. Magnetic metal-organic frameworks. Chem. Soc. Rev. 2009, 38, 1353-1379. [CrossRef] [PubMed]

12. Allendorf, M.D.; Bauer, C.A.; Bhakta, R.K.; Houk, R.J.T. Luminescent metal-organic frameworks. Chem. Soc. Rev. 2009, 38, 1330-1352. [CrossRef] [PubMed]

13. Murray, L.J.; Dinca, M.; Long, J.R. Hydrogen storage in metal-organic frameworks. Chem. Soc. Rev. 2009, 38, 1294-1314. [CrossRef] [PubMed]

14. Wilmer, C.E.; Snurr, R.Q. Large-Scale generation and screening of hypothetical metal-organic frameworks for applications in gas storage and separations. In Prediction and Calculation of Crystal Structures: Methods and Applications; Atahan-Evrenk, S., Aspuru-Guzik, A., Eds.; Springer International Publishing: Cham, Switzerland, 2014; pp. 257-289.

15. Kitagawa, S.; Kitaura, R.; Noro, S.-I. Functional porous coordination polymers. Angew. Chem. Int. Ed. 2004, 43, 2334-2375. [CrossRef] [PubMed]

16. Biradha, K.; Sarkar, M.; Rajput, L. Crystal engineering of coordination polymers using $4,4^{\prime}$-bipyridine as a bond between transition metal atoms. Chem. Commun. 2006, 0, 4169-4179. [CrossRef] [PubMed]

17. Mei, J.; Leung, N.L.C.; Kwok, R.T.K.; Lam, J.W.Y.; Tang, B.Z. Aggregation-induced emission: Together we shine, united we soar! Chem. Rev. 2015, 115, 11718-11940. [CrossRef] [PubMed]

18. Hong, Y.; Lam, J.W.Y.; Tang, B.Z. Aggregation-induced emission. Chem. Soc. Rev. 2011, 40, 5361-5388. [CrossRef] [PubMed]

19. Liang, J.; Tang, B.Z.; Liu, B. Specific light-up bioprobes based on AIEgen conjugates. Chem. Soc. Rev. 2015, 44, 2798-2811. [CrossRef] [PubMed]

20. Cai, Y.; Gui, C.; Samedov, K.; Su, H.; Gu, X.; Li, S.; Luo, W.; Sung, H.H.Y.; Lam, J.W.Y.; Kwok, R.T.K.; et al. An acidic $\mathrm{pH}$ independent piperazine-TPE AIEgen as a unique bioprobe for lysosome tracing. Chem. Sci. 2017, 8, 7593-7603. [CrossRef]

21. Zhou, Z.; He, C.; Yang, L.; Wang, Y.; Liu, T.; Duan, C. Alkyne activation by a porous silver coordination polymer for heterogeneous catalysis of carbon dioxide cycloaddition. ACS Catal. 2017, 7, 2248-2256. [CrossRef]

22. Wang, L.; Wang, W.; Xie, Z. Tetraphenylethylene-based fluorescent coordination polymers for drug delivery. J. Mater. Chem. B Mater. Biol. Med. 2016, 4, 4263-4266. [CrossRef]

23. Lustig, W.P.; Wang, F.; Teat, S.J.; Hu, Z.; Gong, Q.; Li, J. Chromophore-Based luminescent metal-organic frameworks as lighting phosphors. Inorg. Chem. 2016, 55, 7250-7256. [CrossRef] [PubMed] 
24. Hu, Z.; Huang, G.; Lustig, W.P.; Wang, F.; Wang, H.; Teat, S.J.; Banerjee, D.; Zhang, D.; Li, J. Achieving exceptionally high luminescence quantum efficiency by immobilizing an AIE molecular chromophore into a metal-organic framework. Chem. Commun. 2015, 51, 3045-3048. [CrossRef] [PubMed]

25. Sun, H.-L.; Jiang, R.; Li, Z.; Dong, Y.Q.; Du, M. Novel $(4,8)$-connected scu coordination framework constructed by tetrakis(4-benzoic acid)ethylene. CrystEngComm 2013, 15, 1669-1672. [CrossRef]

26. Shustova, N.B.; Cozzolino, A.F.; Reineke, S.; Baldo, M.; Dincă, M. Selective turn-on ammonia sensing enabled by high-temperature fluorescence in metal-organic frameworks with open metal sites. J. Am. Chem. Soc. 2013, 135, 13326-13329. [CrossRef] [PubMed]

27. Zhang, M.; Saha, M.L.; Wang, M.; Zhou, Z.; Song, B.; Lu, C.; Yan, X.; Li, X.; Huang, F.; Yin, S.; et al. Multicomponent platinum(II) cages with tunable emission and amino acid sensing. J. Am. Chem. Soc. 2017, 139, 5067-5074. [CrossRef] [PubMed]

28. Medishetty, R.; Nalla, V.; Nemec, L.; Henke, S.; Mayer, D.; Sun, H.; Reuter, K.; Fischer, R.A. A new class of lasing materials: Intrinsic stimulated emission from nonlinear optically active metal-organic frameworks. Adv. Mater. 2017, 29, 1605637. [CrossRef] [PubMed]

29. Hu, X.; Wang, Z.; Lin, B.; Zhang, C.; Cao, L.; Wang, T.; Zhang, J.; Wang, C.; Lin, W. Two-Dimensional metal-organic layers as a bright and processable phosphor for fast white-light communication. Chem. Eur. J. 2017, 23, 8390-8394. [CrossRef] [PubMed]

30. Wang, F.; Liu, W.; Teat, S.J.; Xu, F.; Wang, H.; Wang, X.; An, L.; Li, J. Chromophore-immobilized luminescent metal-organic frameworks as potential lighting phosphors and chemical sensors. Chem. Commun. 2016, 52, 10249-10252. [CrossRef] [PubMed]

31. Li, P.; Moon, S.-Y.; Guelta, M.A.; Harvey, S.P.; Hupp, J.T.; Farha, O.K. Encapsulation of a nerve agent detoxifying enzyme by a mesoporous zirconium metal-organic framework engenders thermal and long-term stability. J. Am. Chem. Soc. 2016, 138, 8052-8055. [CrossRef] [PubMed]

32. King, S.C.; Wang, H.; Arman, H.D.; Chen, B. A two-dimensional metal-organic framework composed of paddle-wheel cobalt clusters with permanent porosity. Inorg. Chem. Commun. 2016, 74, 98-101. [CrossRef]

33. Deibert, B.J.; Velasco, E.; Liu, W.; Teat, S.J.; Lustig, W.P.; Li, J. High-Performance blue-excitable yellow phosphor obtained from an activated solvochromic bismuth-fluorophore metal-organic framework. Cryst. Growth Des. 2016, 16, 4178-4182. [CrossRef]

34. Zhang, Q.; Su, J.; Feng, D.; Wei, Z.; Zou, X.; Zhou, H.-C. Piezofluorochromic metal-organic framework: A microscissor lift. J. Am. Chem. Soc. 2015, 137, 10064-10067. [CrossRef] [PubMed]

35. Liu, X.-G.; Wang, H.; Chen, B.; Zou, Y.; Gu, Z.-G.; Zhao, Z.; Shen, L. A luminescent metal-organic framework constructed using a tetraphenylethene-based ligand for sensing volatile organic compounds. Chem. Commun. 2015, 51, 1677-1680. [CrossRef] [PubMed]

36. Kapadia, P.P.; Ditzler, L.R.; Baltrusaitis, J.; Swenson, D.C.; Tivanski, A.V.; Pigge, F.C. Semiconducting organic assemblies prepared from tetraphenylethylene tetracarboxylic acid and bis(pyridine)s via charge-assisted hydrogen bonding. J. Am. Chem. Soc. 2011, 133, 8490-8493. [CrossRef] [PubMed]

37. Kapadia, P.P.; Swenson, D.C.; Pigge, F.C. Influence of halogen bonding interactions in crystalline networks of tetraarylethylene halobenzoyl esters. Cryst. Growth Des. 2012, 12, 698-706. [CrossRef]

38. Kapadia, P.P.; Widen, J.C.; Magnus, M.A.; Swenson, D.C.; Pigge, F.C. Tetrapyridyl tetraphenylethylenes: Supramolecular building blocks with aggregation-induced emission properties. Tetrahedron Lett. 2011, 52, 2519-2522. [CrossRef]

39. Rudd, N.D.; Wang, H.; Teat, S.J.; Li, J. A dual linker metal-organic framework demonstrating ligand-based emission for the selective detection of carbon tetrachloride. Inorg. Chim. Acta 2018, 470, 312-317. [CrossRef]

40. Zhao, S.-S.; Chen, L.; Wang, L.; Xie, Z. Two tetraphenylethene-containing coordination polymers for reversible mechanochromism. Chem. Commun. 2017, 53, 7048-7051. [CrossRef] [PubMed]

41. Zhao, X.; Li, Y.; Chang, Z.; Chen, L.; Bu, X.-H. A four-fold interpenetrated metal-organic framework as a fluorescent sensor for volatile organic compounds. Dalton Trans. 2016, 45, 14888-14892. [CrossRef] [PubMed]

42. Yu, G.; Cook, T.R.; Li, Y.; Yan, X.; Wu, D.; Shao, L.; Shen, J.; Tang, G.; Huang, F.; Chen, X.; et al. Tetraphenylethene-based highly emissive metallacage as a component of theranostic supramolecular nanoparticles. Proc. Natl. Acad. Sci. USA 2016, 113, 13720-13725. [CrossRef] [PubMed]

43. Rudd, N.D.; Wang, H.; Fuentes-Fernandez, E.M.A.; Teat, S.J.; Chen, F.; Hall, G.; Chabal, Y.J.; Li, J. Highly efficient luminescent metal-organic framework for the simultaneous detection and removal of heavy metals from water. ACS Appl. Mater. Interfaces 2016, 8, 30294-30303. [CrossRef] [PubMed] 
44. Jackson, S.L.; Rananaware, A.; Rix, C.; Bhosale, S.V.; Latham, K. Highly fluorescent metal-organic framework for the sensing of volatile organic compounds. Cryst. Growth Des. 2016, 16, 3067-3071. [CrossRef]

45. Hu, Z.; Lustig, W.P.; Zhang, J.; Zheng, C.; Wang, H.; Teat, S.J.; Gong, Q.; Rudd, N.D.; Li, J. Effective detection of mycotoxins by a highly luminescent metal-organic framework. J. Am. Chem. Soc. 2015, 137, 16209-16215. [CrossRef] [PubMed]

46. Gong, Q.; Hu, Z.; Deibert, B.J.; Emge, T.J.; Teat, S.J.; Banerjee, D.; Mussman, B.; Rudd, N.D.; Li, J. Solution processable MOF yellow phosphor with exceptionally high quantum efficiency. J. Am. Chem. Soc. 2014, 136, 16724-16727. [CrossRef] [PubMed]

47. Icli, B.; Solari, E.; Kilbas, B.; Scopelliti, R.; Severin, K. Multicomponent assembly of macrocycles and polymers by coordination of pyridyl ligands to 1,4-bis(benzodioxaborole)benzene. Chem.-Eur. J. 2012, 18, 14867-14874. [CrossRef] [PubMed]

48. Zhou, Z.; Yan, X.; Saha, M.L.; Zhang, M.; Wang, M.; Li, X.; Stang, P.J. Immobilizing tetraphenylethylene into fused metallacycles: Shape effects on fluorescence emission. J. Am. Chem. Soc. 2016, 138, 13131-13134. [CrossRef] [PubMed]

49. Tian, Y.; Yan, X.; Saha, M.L.; Niu, Z.; Stang, P.J. Hierarchical self-assembly of responsive organoplatinum(II) metallacycle-tmv complexes with turn-on fluorescence. J. Am. Chem. Soc. 2016, 138, 12033-12036. [CrossRef] [PubMed]

50. Saha, M.L.; Yan, X.; Stang, P.J. Photophysical properties of organoplatinum(II) compounds and derived self-assembled metallacycles and metallacages: Fluorescence and its applications. Acc. Chem. Res. 2016, 49, 2527-2539. [CrossRef] [PubMed]

51. Pigge, F.C.; Kapadia, P.P.; Swenson, D.C. Halogen bonded networks from pyridyl-substituted tetraarylethylenes and diiodotetrafluorobenzenes. CrystEngComm 2013, 15, 4386-4391. [CrossRef]

52. Gabr, M.T.; Pigge, F.C. Rhenium tricarbonyl complexes of AIE active tetraarylethylene ligands: Tuning luminescence properties and HSA-specific binding. Dalton Trans. 2017, 46, 15040-15047. [CrossRef] [PubMed]

53. Gabr, M.T; Pigge, F.C. A turn-on AIE active fluorescent sensor for $\mathrm{Hg}^{2+}$ by combination of 1,1-bis(2-pyridyl) ethylene and thiophene/bithiophene fragments. Mater. Chem. Front. 2017, 1, 1654-1661. [CrossRef]

54. Gabr, M.T.; Pigge, F.C. A selective fluorescent sensor for $\mathrm{Zn}^{2+}$ based on aggregation-induced emission (AIE) activity and metal chelating ability of bis(2-pyridyl)diphenylethylene. Dalton Trans. 2016, 45, 14039-14043. [CrossRef] [PubMed]

55. Bis, J.A.; Zaworotko, M.J. The 2-aminopyridinium-carboxylate supramolecular heterosynthon: A robust motif for generation of multiple-component crystals. Cryst. Growth Des. 2005, 5, 1169-1179. [CrossRef]

56. Infantes, L.; Motherwell, S. Water clusters in organic molecular crystals. CrystEngComm 2002, 4, 454-461. [CrossRef]

57. Batten, S.R.; Robson, R. Interpenetrating nets: Ordered, periodic entanglement. Angew. Chem. Int. Ed. 1998, 37, 1460-1494. [CrossRef]

58. Shan, N.; Bond, A.D.; Jones, W. Crystal engineering using 4, $4^{\prime}$-bipyridyl with di- and tricarboxylic acids. Cryst. Eng. 2002, 5, 9-24. [CrossRef]

(c) 2018 by the authors. Licensee MDPI, Basel, Switzerland. This article is an open access article distributed under the terms and conditions of the Creative Commons Attribution (CC BY) license (http://creativecommons.org/licenses/by/4.0/). 